\title{
Political Leaders' Communication: A Twitter Sentiment Analysis during Covid-19 Pandemic
}

\author{
Manpreet Kaur ${ }^{1}$, Rajesh Verma ${ }^{2}$, Sandeep Ranjan ${ }^{3}$ \\ ${ }^{1}$ ORCID iD: 0000-0001-8646-9616, GNA University, Sri Hargobindgarh, Phagwara- \\ Hoshiarpur Road, Phagwara, Punjab 144401, India \\ ${ }^{2}$ ORCID iD: 0000-0003-2363-552X, Lovely Professional University, Jalandhar-Delhi, \\ Grand Trunk Road, Phagwara, Punjab 144411, India \\ ${ }^{3}$ ORCID iD: 0000-0002-4440-9348, Apeejay Institute of Management \& Engineering \\ Technical Campus, Rama Mandi, Hoshiarpur Road, Jalandhar, Punjab 144007, India \\ *Corresponding author, e-mail: manpreetkaur@gnauniversity.edu.in
}

\begin{abstract}
The pandemic made it critical for political leaders to intensify measures in fight against Covid-19 and one such measure was building trust among public through communication. With exponential growth in reach of social media, while state political leaders have progressively used internet for election campaigns, limited studies have explored as to how leaders use this medium to communicate during crisis, what kind of information do they share and what are common issues addressed. This paper, using qualitative research design, analyses Indian political leaders' communication on Twitter. Sentiment Analysis was carried to identify and extract subjective information in leaders' communication using 29 Indian political leaders, where in 12.128 tweets were extracted. Subjectivity scores depicted more than half of leaders had shared fact-based information, and Polarity scores indicated that almost $90 \%$ of leaders shared positive or neutral information thus leading to an inference that leaders share more of facts based and positive or neutral information rather than statements in form of opinions.
\end{abstract}

Keywords: Sentiment Analysis, State Political Leaders, India, Covid-19, Twitter.

\section{Introduction}

On 11 March 2020, WHO pronounced a Covid-19 as pandemic. According to (Gates, 2021), coronavirus is communicated successfully and is spread by contact transmission and respiratory beads. State pioneers needed to respond the present circumstance and illuminate residents regarding the steps to be taken to forestall Covid19 spread. Likewise, they are required to illuminate residents about governmental actions. There are numerous approaches to illuminate people in general. For instance, pioneers might decide to advise the public through interpersonal organizations, as it is an ideal method to illuminate individuals quickly. Interpersonal organizations give the likelihood to educate general society continuously about a circumstance. It is significant to rapidly illuminate the general population during crises like Covid-19. Twitter, an informal organization having more than 330 million month to month dynamic clients as per Statista (2021). Undoubtedly, a few chiefs have utilized this platform to advise general society. This paper dissects the number of pioneers Twitter usage to illuminate the general population, the way it is being used. All the more explicitly, it is centered around the development of Twitter supporters.

According to Sheldon, P. \& Bryant, (2016), A few mass correspondence hypotheses are utilized and applied to web-based media. Author recommended that individuals utilize specific media relying upon the requirements (Katz, 1959). Individuals need to satisfy their necessities. Social and mental necessities additionally

Article History: Received August 31, 2020; Revised May 28, 2021; Accepted August 28, 2021; Published September 22, 2021 
vary for every person and are influenced by various components. In the current study, Twitter has been used during the emergency. During such emergency, it is expected that people will use more online information. news utilization expanded gigantically during Covid-19 (Casero-Ripollés, 2020). Researchers found maximum data usage about Covid-19 increases apparent information on the subject, $\&$ it brings about the reception of preventive measures. Individuals can utilize Twitter as a wellspring of information (Igartua et al., 2020).

Parmelee \& Bichard, (2012) analyzed why individuals follow political entertainers on Twitter. They find that there are a few thought processes in utilizing Twitter: comfort, diversion, self-articulation, direction, data chasing, and social utility. These intentions relate with the UGT. During the pandemic, a few of these intentions are available. Twitter is an advantageous stage for data as people just need a versatile or PC screen. Direction is significant when people need counsel from pertinent entertainers on the proper behavior. For instance, the suggestion by means of Twitter from U.S. lead representatives for inhabitants to remain at home extraordinarily decreased the portability of people during the Covid-19 pandemic (Guy Grossman et al., 2020). Data searchers can without much of a stretch discover what government measures are set up to battle the pandemic and the general condition of the country under the suspicion that the public authority account offers this data. The data got by people has additionally a social utility as people then, at that point can examine with their family or companions what they gained from Twitter. Many examinations have affirmed that specific clients use Twitter essentially as a data looking for medium that satisfies their requirement for data (Hughes et al., 2012). Obviously, the UGT isn't utilized uniquely with Twitter (Sawyer \& Chen, 2012), yet various investigations have inspected other online media like Facebook (Hollenbaugh \& Ferris, 2014) or Instagram (Sheldon, P. \& Bryant, 2016).

As of late, research on political correspondence through Twitter has become more unmistakable in sociology research (A. Jungherr, 2016; Andreas Jungherr et al., 2016) . Twitter is a significant stage since policymakers can utilize its investigation to acquire experiences (Joseph et al., 2017). Obviously, there has been research on the reception of web-based media by world pioneers (Barberá \& Zeitzoff, 2018). Additionally, look at correspondence on Twitter by political leaders as the exploration on every day papers in Spain and Italy has shown that the heroes of the pandemic are particularly legislators (Tejedor et al., 2020). The exploration on the use of Twitter during the Covid-19 pandemic is continuous, yet there have been as of now a few examinations dissecting the effect of Covid-19 on Twitter use.

Various examinations have been distributed that analyzed spreading deception via web-based media during the Covid-19 pandemic (Gruzd \& Mai, 2020). For instance, Pulido et al.(2020) track down that bogus data about the pandemic is tweeted more however retweeted not as much as science-based tweets. Merkley et al. (2020) find that openness to online media is connected with misperceptions concerning fundamental realities about Covid-19. Two investigations have been done on the political polarization during the pandemic. In Canada, Merkley et al. (2020) track down that the political elites and people in general are in a period of cross-hardliner concurrence on the significant issue (for instance friendly separating). In actuality, in the United States, tweets are portrayed by solid political polarization (Jiang et al., 2020). A few examinations have broken down tweets and their substance during the pandemic (AbdAlrazaq (2020) and others have utilized the notion investigation (Manguri et al., 2020). In China, (Chen et al., 2020) inspect the significance of public government via online 
media by investigating resident commitment through web-based media of Chinese focal organizations.

Notwithstanding, there has been just one examination that analyzed state pioneers and their movement on Twitter and this was restricted to the world heads of the Group of Seven (G7). The investigation shows, close by different discoveries, that world heads of the G7 all utilization Twitter with the exception of Angela Merkel (Rufai \& Bunce, 2020). It very well might be useful for world pioneers to utilize Twitter during emergencies and to acquire adherents that could turn into their possible allies. By and large, ascended among populaces during the Covid-19 pandemic (Damien Bol et al., 2021). Likewise, news utilization clarifies support for arrangements that look to restrict the spread of Covid-19 (Cilizoglu et al., 2021). Accordingly, more data from important government sources might assist with working on residents' consistence with government activities.

Wuhan city of China has announced its first instance of respiratory contamination known as Covid on December 31, 2019. On March 11, WHO announced it a worldwide pandemic and named as Covid-19 (World Health Organization, 2020) In India, the primary Covid case was accounted for on January 30, 2020 (Reid, 2020). Later on, it spread through 196 nations, including India. On May 3, 2020 around 3.5 million tainted cases, and 246.736 passing cases were affirmed around the world (Spinney, 2020). Accordingly, to oversee general wellbeing WHO update ideal rules (WHO, 2020b). Wellbeing associations like WHO as well as world pioneers are making an honest effort to convey rules and systems to control the circumstance, for example, counteraction measures, wellbeing and security game plan, prudent bundles and so on (Rufai \& Bunce, 2020). Most of the affected countries reacted with remarkable measures to keep the spread of the contamination by executing certain limitation (Boberg et al., 2020)

Similarly, on March 25, the Indian government took a critical choice of securing the entire country for 21 days which is the greatest lockdown the world has at any point seen, with 1.3 billion residents of India being secured for three weeks (Rahman, 2020). India noticed Janata Curfew, for example Deliberate lockdown for 14 hours on March 22, 2020, as coordinated by PM Modi and liked the front liners by applauding at 5 PM for 5 Minutes (Yadav, 2020). This activity was followed and communicated by state leaders to the general public to a great extent a wherein people took this activity with enthusiasm in case of the epidemic. Also, researchers found that more than half of population retrieve political information from online media (M. Kaur \& Verma, 2018). Therefore, amid early stages of crisis such activities were communicated by leader to the general public by government or political leaders for crisis management. In Moreover, leaders at state-level have more direct contact with the public and have better control and influence to manage the situation at ground level; therefore, their communication plays an imperative role. Feng \& Kirkley, (2021) posit that citizens have positive association with local policy makers which has greater influence on their behaviour than the governments guidelines.

The political leader's social media adoption to have contact with masses has been widely increasing after Arab Spring 2011 and the victory of Barak Obama in 2008 and 2012 (Boulianne, 2020; M. Kaur \& Verma, 2018). Likewise in Indian General Election 2014, social media was adopted by PM Narendra Modi resulted in his winning, afterwards other leaders have initiated using Social media. Similarly, leaders have adopted social media for information dissemination, building networks and managing crisis either natural or social (Khan et al., 2014). (Kadijat et al., 2020) found that tweets 
posted by celebrities had more engagement than ordinary people.

Twitter is a microblogging online media platform that permits two-path correspondence to share thoughts, musings, data, assessment with others in 280 characters. Among the world's leaders, $83 \%$ are accessible on Twitter wherein Donald Trump followed by Narendra Modi, are the most persuasive (Smith, 2020). According to Brandwatch, 2020 report, Twitter has 330 million month to month and 145 million every day dynamic clients. A study that $23 \%$ more Twitter clients in 2020 than the earlier year. In India, development in long range informal communication applications was seen in the midst of the underlying period of the public lockdown, which balances out in ensuing stages (Statista, 2021). Such notoriety and upgraded reception of Twitter has spurred me to utilize Twitter for the current examination. Besides, another justification choosing Twitter is the accessibility of subjective information and having checked records of pioneers that are more averse to occur on Facebook and Instagram (Hasan et al., 2018). Additionally, Facebook hosts limited third-get-together information extraction after the Cambridge Analytica case (Cadwalladr, 2018).

Individuals for the most part follow the pioneers with their equivalent belief system (Boutet et al., 2013) making huge impact and concur with the tweets posted (Lin \& Himelboim, 2019) or resounding the inclination communicated in a tweet. For the most part, people are more similar to show commitment for interesting and persuasive posts rather than a message containing anxiety and outrage (Barsade, 2020; Borah, 2016) featured the contagion effect of passing on sure feelings on building an uplifting perspective. Given this evidence, people who follow the pioneer on Twitter will likely reverberate the sentiments contained in the pioneer's tweets. Also Lewis (2000), inspected pioneers feelings and their effect on supporters utilizing recorded talks and discovered impartial feelings have higher viability than irate or miserable feelings of pioneers. Likewise, pioneers who had shown negative feelings shown less eagerness among the adherents. In this way, feeling discovery is a basic space of study in administration correspondence during an emergency. During Covid-19, positive and trust found to be most common emotions whenever leaders tried to issue new guidelines (M. Kaur et al., 2021).

Although political leaders have increasingly adopted social media like Twitter for campaigning and elections (M. Kaur \& Verma, 2018; Kruikemeier, 2014), it remains less explored as to how they communicate during emergencies like Covid-19 via Twitter. According to Brandwatch, Twitter is a microblogging social media platform to share ideas, thoughts, information, opinion with other. As per statistics, twitter has 330 million active users per month, and 145 million uses on daily basis. Among the world's leaders, 83 percent are available on Twitter wherein Donald Trump followed by Narendra Modi, are most influential.

Keeping in mind, this study tries to the address the research question; How state leaders communicate on Twitter during emergencies like Covid-19? What kind of information do political leaders share during emergency management? (factual or opinion based) What are the common topics addressed by leaders to cope with the emergency?

The paper will contribute to the academic literature and practitioners such as political leaders. Although majority of studied have explored leaders crisis communication at organizational level, there is dearth of study which focuses on political context. The current study has considered tweets from local or state leaders which is novelty in itself because previous authors either have used world leaders or 
public tweets to explore their sentiments. As per researcher's knowledge, this study has applied subjectivity based sentiment analysis using Python during Covid-19 which is more robust method to explore the sentiments, however, past study have employed NRC based sentiment analysis. Apart from sentiments, the kind of content communicated in the form of topics by local leader associated with Covid-19 in India is compared.

\section{Methods}

The current study employs a qualitative research design for content analysis and sentiment analysis. Total 53 days from date of global pandemic Covid-19 declaration by WHO, i.e. March 11, 2020 (WHO, 2020a), to Indian Lockdown 2.0, i.e. May 3, 2020 (Leo, 2020), is considered, wherein 12,128 tweets fetched from official handles of 29 Indian political leaders using API. Politicians are interested in identifying influential nodes in the society and social networks (Ullah \& Lee, 2016). Doing so helps them to spread their word to the masses. Often most of the politicians are fairly popular among the people and their opinions rapidly transmit to the general public (Phillips et al., 2021). The political leaders form communities on the social media where their word spreads in the form of online word of mouth. The online word of mouth in the social network communities propagates to connected nodes and may cross the geopolitical boundaries as a viral spread of messages (Ranjan, 2018).

The present research was focused on the political leaders from all the states and union territories of India. Many Indian states and union territories have population of the order of 100 millions and so the political leaders from these regions are connected to a large number of people on the social networks like Twitter. Some of the leaders from smaller states of India have very less followers owing to the small population of their states. Still these leaders have been included in the research as their information dissemination caught the attention of the general public.

As India has 22 officially recognized languages, some Twitter users post their opinion either in their vernacular language using its script or using English characters. Before analysis, the data was translated into English using a translator and passed through text preprocessing such as removing all the unnecessary data such as URLs, @ users, punctuations, stop words, white spaces etc. to get more accurate and relevant results from the dataset (Stier et al., 2018). Focusing to measure the response of political leaders amid the Covid-19 pandemic, the most used topics by each leader were identified and visualized using 'ggplot'. Moreover, we also used subjectivity and polarity analysis for measuring sentiments using TextBlob. The values of subjectivity range between 0 1 , where in values closer to 0 represent fact-based information, and 1 represents opinionbased information. Similarly, polarity depicts the context of opinion, i.e. positive, negative or neutral, and values range from -1 to +1 (R. Kaur \& Ranjan, 2020). Subjectivity and polarity for each tweet was calculated and the average for a leader was calculated along with the sentiment score given by taking the product of subjectivity and polarity values. The dataset was analyzed to reveal patterns or similarities in the words, hashtags and word pairs.

\section{Results}

This section elaborates the results of the analysis in line with objectives along with discussions. Firstly, to explore how state leaders communicate on Twitter during emergencies like Covid-19, profiles of leaders and the frequency of their tweets were observed. Considering all states and UTs of India, 29 state leaders have been found to 
have verified accounts. Among them, the topmost followed leaders are:

First, Arvind Kejriwal (ArvindKejriwal), a popular leader in India quit his bureaucratic job to enter politics by establishing AAM ADMI PARTY and became the Chief Minister of New Delhi. He has 18.6 million followers on Twitter and is highly influential. During the experiment study period, his 370 tweets fetched a polarity 0.47 , subjectivity 0.52 . The value for the product of polarity and subjectivity is 0.24 with an overall sentiment score of 28.91 averaging 0.08. Second, Yogi Aditya Nath (myogiadityanath), the Chief Minister of Uttar Pradesh has 8.8 million followers on Twitter. The average polarity, subjectivity and the product of polarity and subjectivity of his tweets are all 0. His 213 tweets fetched an overall sentiment score of 213 averaging 0.08. Third, Sarbananda Sonowal (sarbanandsonwal), the Chief Minister of Assam state has 6.3 million followers. The average polarity, subjectivity and the product of polarity and subjectivity of his tweets are $0,0.07$ and 0 respectively. His 213 tweets fetched an overall sentiment score of 27.99 averaging 0.09. Fourth, The Chief Minister of Nagaland state, Km. Neiphiu Rio (Neiphiu_Rio) has 5.5 million Twitter followers. The average polarity, subjectivity and the product of polarity and subjectivity of his tweets are $0.1,0.44$ and 0.04 respectively. His 213 tweets fetched an overall sentiment score of 213 averaging 0.08 .

Fifth, The Chief Minister of West Bengal state, Mamata Banerjee (MamataOfficial) has 4.7 million followers. The average polarity, subjectivity and the product of polarity and subjectivity of her tweets are 0,1 and 0 respectively. His 50 tweets fetched an overall sentiment score of 4.61 averaging 0.09. Sixth, The Chief Minister of Bihar state, Nitish Kumar (NitishKumar) has 2.7 million followers. The average polarity, subjectivity and the product of polarity and subjectivity of his tweets are 0,1 and 0 respectively. His 50 tweets fetched an overall sentiment score of 4.61 averaging 0.09. Seventh, The Chief Minister of Gujarat state, Vijaybhai R. Rupani (vijayrupanibjp) has 2.6 million followers. The average polarity, subjectivity and the product of polarity and subjectivity of his tweets are $0.1,0.4$ and 0.04 respectively. His 404 tweets fetched an overall sentiment score of 21.54 averaging 0.05. Eighth, The Chief Minister of Haryana state, Manohar Lal (mlkhattar) has 1.7 million followers. The average polarity, subjectivity and the product of polarity and subjectivity of his tweets are $-0.5,1$ and -0.5 respectively. His 1225 tweets fetched an overall sentiment score of 84.01 averaging 0.07 .

Ninth, The Chief Minister of Andhra state, YS Jagan Mohan Reddy (Ysjagan) has 1.5 million followers. The average polarity, subjectivity and the product of polarity and subjectivity of his tweets are $0.35,0.55$ and 0.19 respectively. His 14 tweets fetched an overall sentiment score of 2.44 averaging 0.17. Tenth, The Chief Minister of Rajasthan state, Ashok Gehlot (ashokgehlot51) has 1.4 million followers. The average polarity, subjectivity and the product of polarity and subjectivity of his tweets are all 0 . His 1384 tweets fetched an overall sentiment score of 48.32 averaging 0.03 . The Chief Ministers of the above-mentioned states have followers in millions. Therefore, citizens like to get in touch and seek information from these leaders the most. However, Ashok Gehlot (1384), Hemant Soren (1281) and Manohar Lal (1225) are found to be more frequent in sharing information amid epidemic. The rest of the Chief Ministers have less than 1 million followers but yet their influence is significant and therefore included in the study. Eleventh, The Chief Minister of Maharashtra state, Shivraj Singh Chouhan (ChouhanShivraj) has 775 thousand followers. The average polarity, subjectivity and the product of polarity and subjectivity of his tweets are $0.6,0.9$ and 0.54 respectively. 
His 939 tweets fetched an overall sentiment score of 59.05 averaging 0.06.

Twelfth, The Chief Minister of Meghalaya state, Conrad Kongkal Sangma (SangmaConrad) has 749 thousand followers. The average polarity, subjectivity and the product of polarity and subjectivity of his tweets are all 0 . His 255 tweets fetched an overall sentiment score of 11.29 averaging 0.04. Thirteenth, The Chief Minister of Karnataka state, B. S. Yediyurappa (BSYBJP) has 607 thousand followers. The average polarity, subjectivity and the product of polarity and subjectivity of his tweets are all 0 . His 129 tweets fetched an overall sentiment score of 9.23 averaging 0.07. Fourteenth, The Chief Minister of Maharashtra state, Uddhav Thackeray (OfficeofUT) has 476 thousand followers. The average polarity, subjectivity and the product of polarity and subjectivity of his tweets are $0.75,0.6$ and 0.45 respectively. His 160 tweets fetched an overall sentiment score of 8.31 averaging 0.05. Fifteenth, The Chief Minister of Kerala state, Pinarayi Vijayan (vijayanpinarayi) has 433 thousand followers. The average polarity, subjectivity and the product of polarity and subjectivity of his tweets are all 0 . His 103 tweets fetched an overall sentiment score of 8 averaging 0.08. Sixteenth, The Chief Minister of Jharkhand state, Hemant Soren (HemantSorenJMM) has 317 thousand followers. The average polarity, subjectivity and the product of polarity and subjectivity of his tweets are $-0.4,0.6$ and -0.2 respectively. His 1281 tweets fetched an overall sentiment score of 64.89 averaging 0.05 .

Seventeenth, The Chief Minister of Chhattisgarh state, Bhupesh Baghel (bhupeshbaghel) has 247 thousand followers. The average polarity, subjectivity and the product of polarity and subjectivity of his tweets are $0.7,0.6$ and 0.42 respectively. His 632 tweets fetched an overall sentiment score of 21.77 averaging 0.03. Eighteenth, The Chief Minister of Uttarakhand state, Trivendra Singh Rawat (tsrawatbjp) has 213 thousand followers. The average polarity, subjectivity and the product of polarity and subjectivity of his tweets are $0.1,0.4$ and 0.04 respectively. His 378 tweets fetched an overall sentiment score of 24.12 averaging 0.06. Nineteenth, The Chief Minister of Tripura state, Biplab Kumar Deb (BjpBiplab) has 122 thousand followers. The average polarity, subjectivity and the product of polarity and subjectivity of his tweets are 0.1 , 0.1 and 0.01 respectively. His 764 tweets fetched an overall sentiment score of 65.94 averaging 0.09. Twentieth, The Chief Minister of Himachal Pradesh state, Jairam Thakur (jairamthakurbjp) has 108 thousand followers. The average polarity, subjectivity and the product of polarity and subjectivity of his tweets are $0.43,0.66$ and 0.28 respectively. His 618 tweets fetched an overall sentiment score of 42.11 averaging 0.07.

Twenty-first, The Chief Minister of Punjab state, Capt. Amarinder Singh (capt_amarinder) has 64.2 thousand followers. The average polarity, subjectivity and the product of polarity and subjectivity of his tweets are all 0 . His 261 tweets fetched an overall sentiment score of 26.78 averaging 0.1. Twenty-second, The Chief Minister of Tamil Nadu state, Thiru Edappadi K. Palaniswami (CMOTamilNadu) has 56 thousand followers. The average polarity, subjectivity and the product of polarity and subjectivity of his tweets are all 0. His 663 tweets fetched an overall sentiment score of 20.77 averaging 0.03. Twenty-third, The Chief Minister of Puducherry Union Territory, V. Narayanasamy (Vnarayanasami) has 47.2 thousand followers. The average polarity, subjectivity and the product of polarity and subjectivity of his tweets are $0.25,0.33$ and 0.08 respectively. His 520 tweets fetched an overall sentiment score of 12.84 averaging 0.02. Twenty-fourth, The Chief Minister of Goa State, Pramod Sawant (DrPramodPSawant) has 47.1 thousand followers. The average polarity, subjectivity and the product of polarity and subjectivity of his tweets are $0.5,0.5$ and 0.25 
respectively. His 235 tweets fetched an overall sentiment score of 19.72 averaging 0.08 . Twenty-fifth, The Chief Minister of Odisha state, Naveen Patnaik (Naveen_Odisha) has 37.4 thousand followers. The average polarity, subjectivity and the product of polarity and subjectivity of his tweets are $0.15,0.32$ and 0.04 respectively. His 118 tweets fetched an overall sentiment score of 7.87 averaging 0.07. Twenty-sixth, The Chief Minister of Telangana state, K Chandrasekhar Rao (TelanganaCMO) has 26 thousand followers. The average polarity, subjectivity and the product of polarity and subjectivity of his tweets are $0.33,1$ and 0.33 respectively. His 383 tweets fetched an overall sentiment score of 16.21 averaging 0.04. Twenty-seventh, The Chief Minister of Mizoram state, Pu Zoramthanga (ZoramthangaCM) has 5789 followers. The average polarity, subjectivity and the product of polarity and subjectivity of his tweets are -0.2 , 0.5 and -0.1 respectively. His 65 tweets fetched an overall sentiment score of 3.3 averaging 0.05. Twenty-eighth, The Chief Minister of Sikkim state, PS Golay (GolayPs) has 1328 followers. The average polarity, subjectivity and the product of polarity and subjectivity of his tweets are all 0 . His 65 tweets fetched an overall sentiment score of 3.3 averaging 0.05. And twenty-ninth, The Chief Minister of Arunachal Pradesh state, Pema Khandu (ArunachalCMO) has 277 followers. The average polarity, subjectivity and the product of polarity and subjectivity of his tweets are all 0 respectively. His 429 tweets fetched an overall sentiment score of 27 averaging 0.06 .

Furthermore, the highest number of posts was observed when there is an announcement of JanataCurfew (Voluntary Curfew) on 22 March 2020 and Lockdown 0.1 i.e. 25 March 2020 and Lockdown 0.2 i.e. 14 April 2020. Variations in the tweet frequency is found which are confirming the observation of Agarwal \& Toshniwal (2019) which revealed that not all leaders are active on Twitter. In addition to that, we found that before introducing any guidelines, leaders were found to be more active than other days (Figure 1).

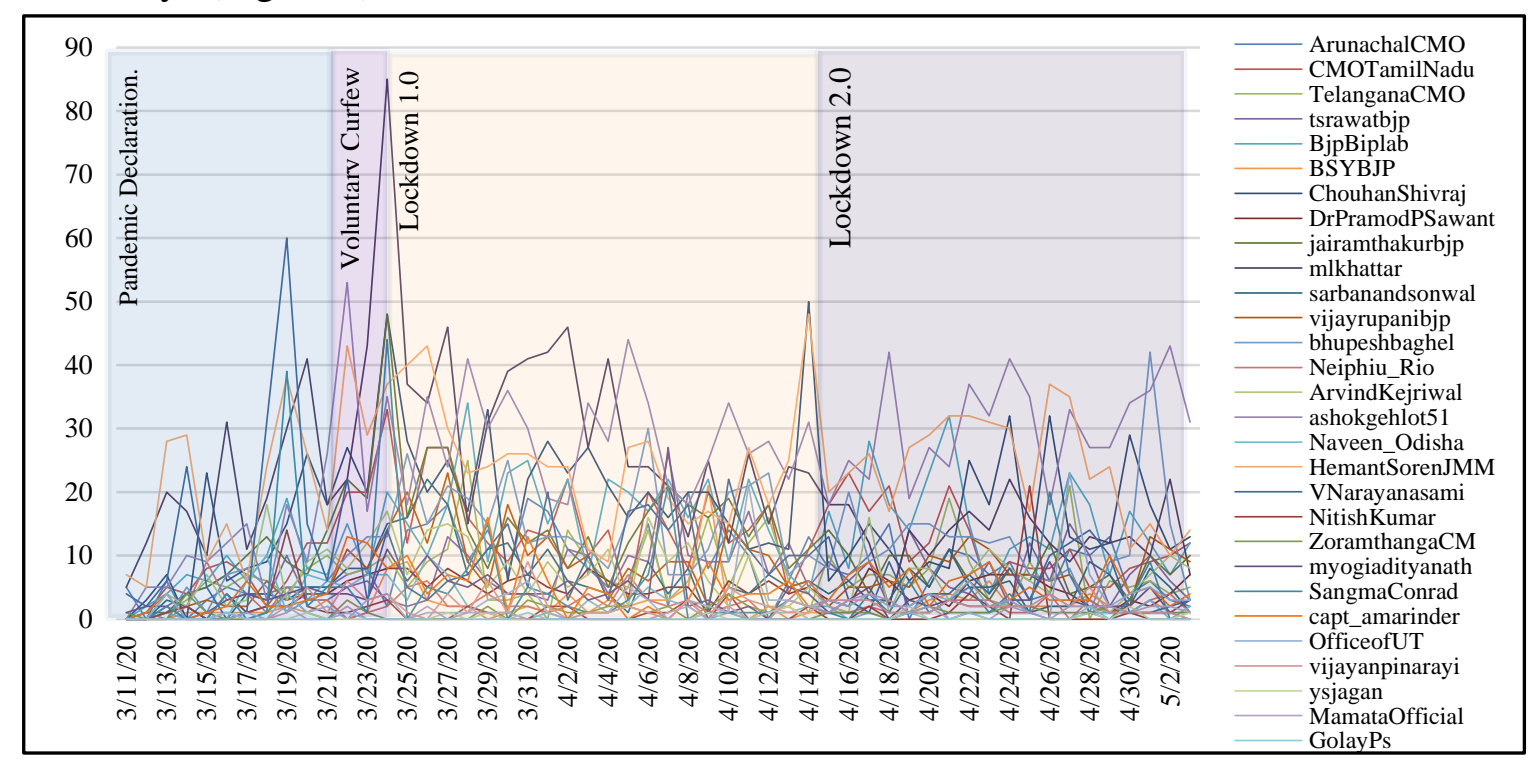

Figure 1. Frequency of Tweets (Datewise) (source: Author's analysis)

We applied sentiment analysis using subjectivity and polarity analysis to explore that information shared by leaders is factual or opinion-based. Subjectivity analysis deals with emotion reflected in the text whereas polarity analysis deals with positive, neutral or negative or aspects. Results of analyzing subjectivity revealed that more than half of the leaders had shared exclusively fact-based information, whereas four leaders have shared opinion-based information. Similarly, results of polarity analysis indicate

Jurnal The Messenger, Vol. 13, No. 1 (2021), pp. 45-62 
almost $90 \%$ of leaders share positive or neutral information to the public wherein more than one-third depicts the neutral context. However, only three leaders are found with negative information more. Overall, positive sentiments were observed.

Therefore, in an emergency like Covid-19, leaders try to cope with the situation by sharing more facts-based or positive information rather than passing statements in the form of opinions or sentiments because, in such situations, the public feels distressed and negative. Also, the public requires the right information in the right context so that their mental health should not suffer.

Further, Figure 2 depicts the common topics to communications by different political leaders to manage an emergency like Covid-19. Governmental actions on Covid-19 for the people were discussed by the national political leader as the most words are identified as government, people, and Covid-19. Moreover, daily updates, guidelines, awareness campaigns, appeals and actions were shared to generate awareness. Most common information was regarding awareness of state and nation policies such as curfew, lockdown; preventive measures like do not panic, stay home, maintain social distancing etc. Likewise, financial and non-financial assistance in the form of funds, reliefs, donations, contributions, ration, food; and boosting morale and appreciation of contributor's weather front-liners like health workers, police, cleaning workers excetera or people who have contributed financially.

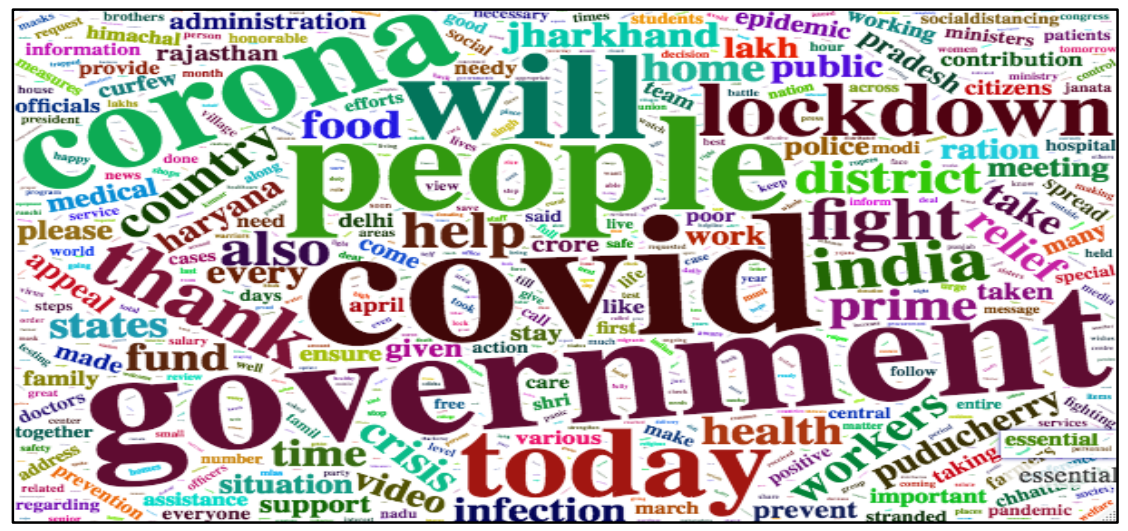

Figure 2. Frequency of Tweets (source: Author's analysis)

Additionally, analysis is carried out to compare political leaders' responses by identifying the most common topics to information having higher engagements in terms of retweets amid Covid-19. Figure 3 reveals Pema Khandu, Chief minister of Arunachal Pradesh focused on financial assistance scheme called Pradhan Mantri Greeb Kalyan Yojana (PMGKY), tests conducted, country and medical facilities. Likewise, New Delhi leader Arvind Kejriwal mentioned more about arrangements, shelter, schools, daily updates, whereas, Rajasthan's Ashok Gehlot posts considered Covid as the biggest disaster and mentioned protection in his most retweeted posts. Chhattisgarh Chief Minster Bhupesh Baghel focused more on morale-boosting, immunity, discussion, on the other hand, Biplab Kumar Deb from Tripura expressed regarding daily information, updates, actions, messages and medical treatment like patients treated or discharged. Karnataka leader B. S. Yediyurappa highlighted assistance in the form of food, relief, fund along with the campaign "IndiaFightsConona". Punjab Chief Minister Capt. Amarinder Singh focused more on appreciating front-liner by campaign "IAmHarjeetSingh" and information of situations and decisions like a curfew. Madhya Pradesh leader Shivraj Singh Chouhan emphasis his party, victory on the success of "JanataCurfew" and curfew. The common topics found the tweet datasets of these 
leaders have been visualized in Figure 3 and labeled as group 1.

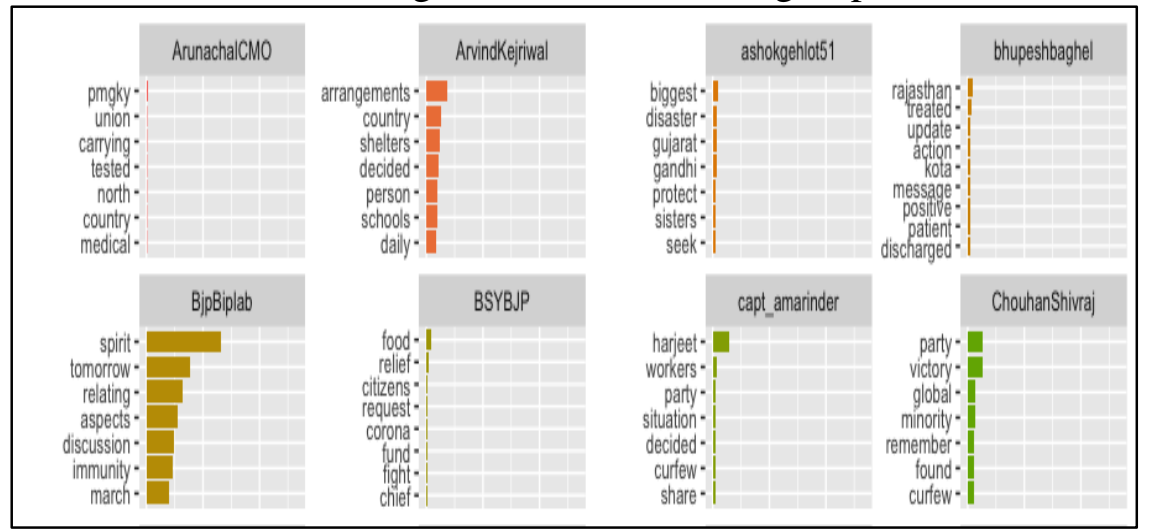

Figure 3. Common Topics in Tweet Dataset Group 1 (source: Author's analysis)

Thiru Edappadi K. Palaniswami, CM of Tamil Nadu spotlighted care for mothers, immediate, curfew, video, difficulties and Goa's Pramod Sawant mentioned patients, doctors, staff, JanataCurfew. Hemant Soren from Jharkhand concentrates on appeals, facilities and appreciation to contributors and Himachal Pradesh's Jairam Thakur stressed more about nature considering the planet as, mother, asked to be healthier and not to panic. West Bengal Chief Minister Mamata Banerjee highlighted the state, health and government and Haryana leader Manohar Lal focused on interaction with the public either by himself by creating an alert for Prime Minister's address in "mannkibaat". Yogi Aditya Nath (Uttar Pradesh), Uddhav Thackeray (Maharashtra) and Vijaybhai R. Rupani (Gujarat) emphasized addressing the public, interactions, appeals, march, campaign, nurses, laborers media and sarpanch. Neiphiu Rio (Nagaland) and Conrad Kongkal Sangma (Meghalaya) posted about appeals, medical facilities, financial assistance, patients, family. Nitish Kumar (Bihar) posted more about the lockdown, government, health-recovered, workers. The common topics found the tweet datasets of these leaders have been visualized in Figure 4 and labeled as group 2.

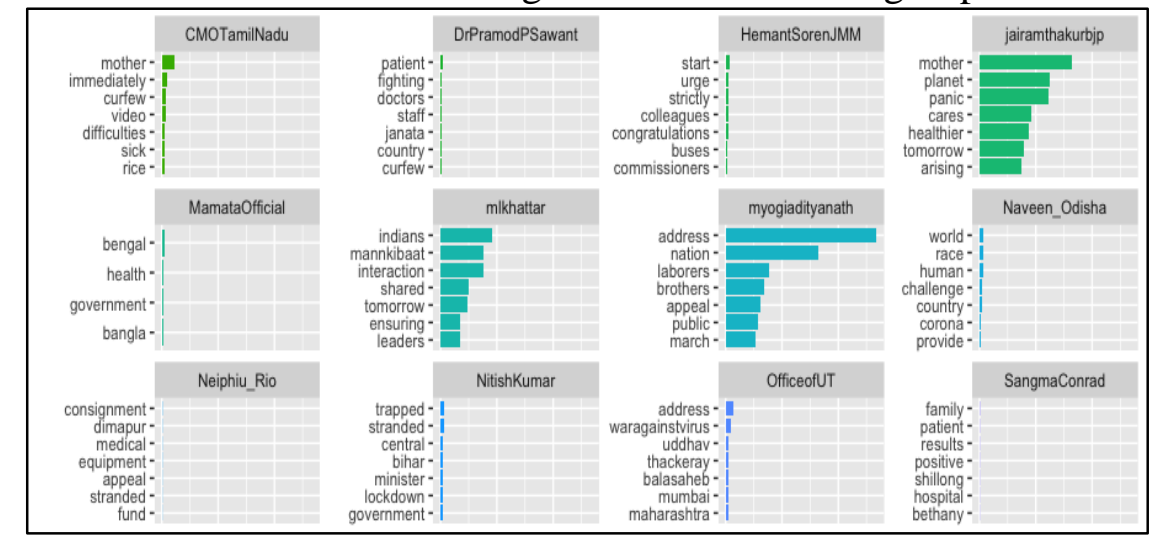

Figure 4. Common Topics in Tweet Dataset Group 2 (source: Author's analysis)

V. Narayanasamy (Puducherry) mentioned relief package and crisis period and Trivendra Singh (Uttarakhand) mentioned society, pandemic, mannkibaat, social distancing, system. Sarbananda Sonowal (Assam) and K Chandrasekhar Rao (Telangana) focused the importance of public and interaction with the public. Pinarayi Vijayan (Kerala) wrote about health workers and recovery from the disease. Trivendra Singh Rawat (Uttarakhand) mentioned society, pandemic and social distancing and $\mathrm{Pu}$ Zoramthanga (Mizoram) wrote about Mizoram, Covid and meeting. The common topics 
found the tweet datasets of these leaders have been visualized in Figure 5 and labeled as group 3.

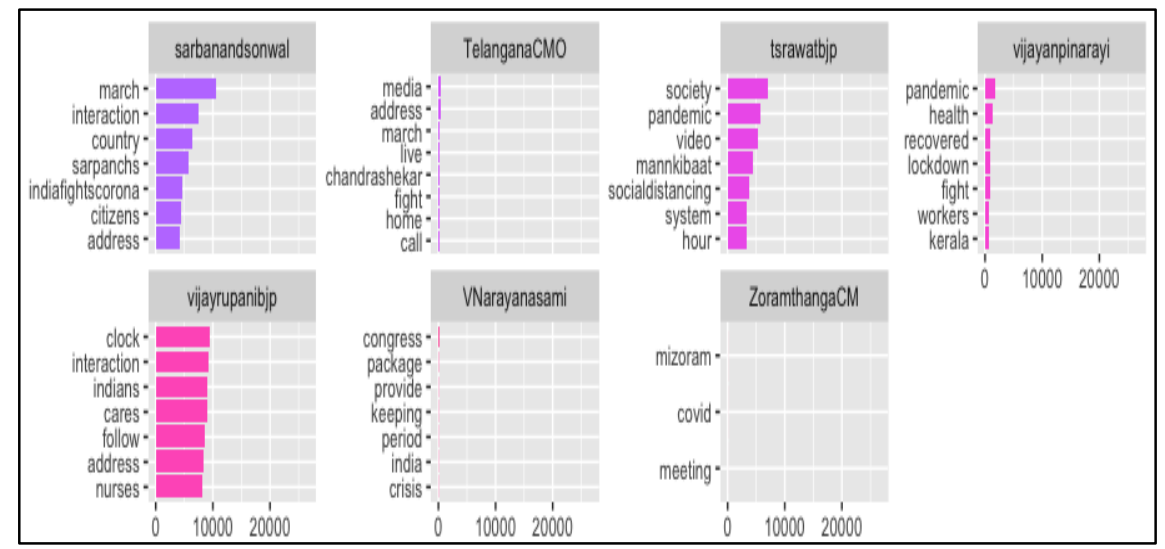

Figure 5. Common Topics in Tweet Dataset Group 3 (source: Author's analysis)

\section{Discussion}

This paper adds to the huge group of academic writing focusing on Covid-19 pandemic. Results revealed that the worldwide spread of Covid-19 pandemic essentially affected the Twitter communication of state pioneers. Twitter is a significant device for state pioneers as it permits them to handily discuss straightforwardly with their residents. They perceive this significance.

While the political pioneers have progressively embraced web-based media such as Twitter for battling \& decisions, it stays limited investigated regarding the way of conveying during crises like Covid-19 pandemic \& sentiments engrossed towards crisis management. This paper utilized a subjective exploration plan to investigate pioneer's reaction during Covid-19 outbreak. Keeping in mind Covid-19 pandemic, applied substance examination and opinion investigation wherein recurrence of most continuous words were recognized alongside subjectivity and extremity investigation on 12,128 tweets got from verified handles of 29 Indian political pioneers from March 11, 2020, till May 3, 2020.

Literature supported state chiefs played significant impact in communication using Twitter during the Covid-19 pandemic. Casero-Ripollés (2020) revealed that individuals used Covid-19 pandemic news using social media for better wellbeing. Wherein, Twitter is one of the media which can be used for getting information Subsequently, state chiefs disseminated information on official Twitter handles, data looking for residents ought to be keen on it. In the investigation of why individuals follow political entertainers, Parmelee and Bichard (2012) revealed that one of the intentions in utilizing Twitter is data extraction. Different examinations presumed that for certain individuals data looking for is the essential thought process in utilizing Twitter (Hughes et al., 2012). Amid the wellbeing crisis which adds to expanded news utilization, referenced thought processes should influence Twitter devotees mean records that give wellbeing and other important data during seasons of emergency. For sure, discoveries of this investigation affirm that most state pioneers give Covid-19 pandemic information and their number of Twitter adherents incredibly expanded amid pandemic.

Undoubtedly, all political leaders try to manage and control emergencies like Covid-19 by implementing different communication strategies on social media like Twitter. Current study found that positive and fact-based information is more likely to 
be shared by leaders than emotional or opinion-based information. This will help in making a positive attitude and the public will not feel distressed or negative by providing the right information in the right context to keep their mental health balanced while (Limaye et al., 2020) focused on building trust amid Covid-19 on social media.

Furthermore, the second finding from web-based media investigation identifies with what words pioneers utilized. While it is feasible to communicate the substance of tweets by specific gatherings on Twitter in an unexpected way, quite possibly the best ways is to imagine it as word mists. It is a generally utilized strategy in web-based media investigation (Grover et al., 2020) the content analysis depicts, higher engagement in terms of retweets is found on topics such as nonfinancial financial assistance, moraleboosting, appeals, updates, information and guidelines, curfew and lockdown, and health facilities. Such information is useful for getting public support on actions taken or shared by leaders.

Results uncovered that political pioneers laid a lot of spotlight on day by day refreshes, rules, mindfulness crusades, requests, activities, preventive measures, monetary and non-monetary help, boosting assurance and enthusiasm for front-liners during the pestilence. Likewise, most of the data shared is found as authentic than assessment based. These discoveries are needed for pioneers to keep up with dynamic web-based media presence as well as to pick the points and feelings while imparting data to the general population in the midst of such crises.(O'Connor et al., 2010) highlighted a strong association between Sentiments and leaders.

This study also contributed considering the Twitter usage by state leaders amid Covid-19 as previous studies emphasized the importance of leaders and media amid pandemic (Rufai \& Bunce, 2020). Moreover, studies applied manual coding for content analysis (Tang et al., 2018), whereas we used machine learning techniques solely. Also, we examined the information from the leaders' Twitter handles during the pandemic to have leader's strategies and opinions for health management, at the same time other studies gathered data using words or hashtags.

No study is inclusive, therefore this study also have some shortcomings. The present study is limited to Indian political leaders, can be extended to other countries and fields to make it more generalized. The impediment of the examination is that it was not attainable to affirm that adherents are real records of residents. Nonetheless, a similar impediment likewise applies to the pre-pandemic time frame. The examination zeroed in just on Twitter adherent checks and didn't dissect supporters. This is justifiable as the investigation would need to dissect the action of countless Twitter accounts in various time spans. It is extremely challenging to identify whether records are real, particularly in case accounts are latent and don't tweet.

Corresponding to this examination, there is an opportunities for future exploration. It will be particularly fascinating to see whether lawmakers hold recently acquired adherents or regardless of whether clients will unfollow them in enormous numbers when the emergency is finished. It is now conceivable to see that the development rate is diminishing in contrast with March 2020 on account of most of lawmakers. Notwithstanding, it doesn't appear to be reasonable that the emergency will be over soon. Consequently, it is conceivable that there won't be any mass unfollowing soon and that more individuals will utilize Twitter.

\section{Conclusion}

During emergency situation like Covid-19, it is essential for leaders to disseminate

Jurnal The Messenger, Vol. 13, No. 1 (2021), pp. 45-62 
information with public via social media platforms like Twitter, especially when physical or social distancing is recommended. Keeping in mind the exponential growth in reach of social media, political leaders have started using social media for election campaigning but there is dearth of studies which focuses on how they use this medium to communicate during crisis, what kind of information do they share and what are common issues addressed. To filled this gap, this paper adopted qualitative research design to analyze Indian political leaders' communication on Twitter. Sentiment Analysis was carried to identify and extract subjective information in leaders' communication using 12.128 tweets from official handles of 29 Indian political leaders from March 11 till May 3, 2020. Subjectivity scores revealed that more than half of leaders had shared fact-based information, and Polarity scores indicated that almost $90 \%$ of leaders shared positive or neutral information. Hence, leaders share more of facts based and positive or neutral information rather than statements in form of opinions or sentiments. In terms of type of information, the current study revealed that 'daily updates, guidelines, awareness campaigns, appeals, actions, preventive measures, financial and non-financial assistance, boosting morale and appreciation of front-liners' during the pandemic are common topics shared by the leaders which has higher engagement. These findings revealed that during pandemic, leaders should laid focus on fact based information in communication on social media. Based on the findings we recommend that Political leaders are required not only to maintain an active social media presence but also the selection to topics of information and sentiments are equally important in case of emergencies like Covid-19.

\section{Conflict of Interest}

We certify that there is no conflict of interest with any financial, personal, or other relationships with other people or organizations related to the material discussed in the manuscript.

\section{Acknowledgements}

The authors would like to thank Twitter for making this study a successful one by ensuring all the needed data are readily available. Appreciation also goes to coauthors who assisted to crawl data from Twitter to ensure the study is promptly and properly completed.

\section{References}

Abd-Alrazaq, A., Alhuwail, D., Househ, M., Hai, M., \&, \& Shah, Z. (2020). Top concerns of tweeters during the COVID-19 pandemic: A surveillance study. Journal of Medical Internet Research, 22(4). https://doi.org/https://doi.org/10.2196/19016

Agarwal, A., \& Toshniwal, D. (2019). Face off: Travel habits, Road conditions and Trafficcity characteristics bared using Twitte. JOURNAL OF LATEX CLASS FILES, 11(4), 1-17. https://doi.org/10.1109/ACCESS.2019.2917159

Barberá, P., \& Zeitzoff, T. (2018). The new public address system: Why do world leaders adopt social media? International Studies Quarterly, 22(4). https://doi.org/https://doi.org/10.2196/19016

Barsade, S. (2020). The Contagion We Can Control. Harvard Business Review. https://hbr.org/2020/03/the-contagion-we-can-control

Boberg, S., Quandt, T., \& Schatto-Eckrodt, T., Frischlich, L. (2020). Pandemic 
Populism: Facebook Pages of Alternative News Media and the Corona Crisis -A Computational Content Analysis (No. 1). https://arxiv.org/abs/2004.02566

Borah, P. (2016). Political Facebook use: Campaign strategies used in 2008 and 2012 presidential elections. Journal of Information Technology \& Politics, 13(4), 326338. https://doi.org/https://doi.org/10.1080/19331681.2016.1163519

Boulianne, S. (2020). Participation, Twenty Years of Digital Media Effects on Civic and Political. Sage Journals, 47(7), 947-966. https://doi.org/https://doi.org/10.1177/0093650218808186

Boutet, A., Kim, H., \& Yoneki, E. (2013). What's in Twitter, I know what parties are popular and who you are supporting now! Social Network Analysis and Mining, 3(4), 1379-1391. https://doi.org/https://doi.org/10.1007/S13278-013-0120-1

Cadwalladr, C. (2018). 'I made Steve Bannon's psychological warfare tool': meet the data war whistleblower. The Guardian. https://www.theguardian.com/news/2018/mar/17/data-war-whistleblowerchristopher-wylie-faceook-nix-bannon-trump

Casero-Ripollés, A. (2020). Impact of covid-19 on the media system. Communicative and democratic consequences of news consumption during the outbreak. Profesional de La Informacion, 29(2). https://doi.org/https://doi.org/10.3145/EPI.2020.MAR.23

Chen, Q., Min, C., Zhang, W., Wang, G., Ma, X., \& Evans, R. (2020). Unpacking the black box: How to promote citizen engagement through government social media during the COVID-19 crisis. Computers in Human Behavior, 110. https://doi.org/https://doi.org/10.1016/j.chb.2020.106380

Cilizoglu, M., Heinrich, T., \& Kobayashi, Y. (2021). Fighting COVID-19, Foregoing Civil Liberties? ResearchGate. https://doi.org/10.13140/RG.2.2.14801.86882

Damien Bol, Giani, M., Blais, A., \& Loewen, P. J. (2021). The effect of COVID-19 lockdowns on political support: Some good news for democracy? European Journal of Political Research, 60(2), 497-505. https://doi.org/https://doi.org/10.1111/1475-6765.12401

Feng, S., \& Kirkley, A. (2021). Integrating online and offline data for crisis management: Online geolocalized emotion, policy response, and local mobility during the COVID crisis. Scientific Reports, 11(1). https://doi.org/https://doi.org/10.1038/S41598-021-88010-3

Gates. (2021). Responding to covid-19 - a once-in-a-century pandemic? The NEW ENGLAND JOURNAL of MEDICINE, 382, 1667-1669. https://doi.org/https://doi.org/10.1056/NEJMp2003762

Grover, P., Kar, A. K., \& Dwivedi, Y. K. (2020). Understanding artificial intelligence adoption in operations management: insights from the review of academic literature and social media discussions. Annals of Operations Research. https://doi.org/https://doi.org/10.1007/s10479-020-03683-9

Gruzd, A., \& Mai, P. (2020). Going viral: How a single tweet spawned a COVID-19 conspiracy theory on Twitter. Big Data and Society, 7(2). https://doi.org/https://doi.org/10.1177/2053951720938405

Guy Grossman, Kim, S., Rexer, J. M., \& Thirumurthy, H. (2020). Political partisanship influences behavioral responses to governors' recommendations for COVID-19 prevention in the United States. In M. Levi (Ed.), Proceedings of the National Academy of Sciences. https://doi.org/https://doi.org/10.1073/pnas.2007835117 
Hasan, A., Moin, S., Karim, A., \& Shamshirband, S. (2018). Machine Learning-Based Sentiment Analysis for Twitter Accounts. Mathematical and Computational Applications, 23(1), 11. https://doi.org/https://doi.org/10.3390/mca23010011

Hollenbaugh, E. E., \& Ferris, A. L. (2014). Facebook self-disclosure: Examining the role of traits, social cohesion, and motives. Computers in Human Behavior, 30, 50-58. https://doi.org/10.1016/j.chb.2013.07.055

Hughes, D. J., Rowe, M., Batey, M., \& Lee, A. (2012). A tale of two sites: Twitter vs. Facebook and the personality predictors of social media usage. Computers in Human Behavior, 28(2), 561-569. https://doi.org/https://doi.org/10.1016/j.chb.2011.11.001

Igartua, J. J., Ortega, F., \& Calderón, C. A. (2020). Communication use in the times of the coronavirus. A cross-cultural study. Profesional de La Informacion, 29(3), 115. https://doi.org/https://doi.org/10.3145/epi.2020.may.18

Jiang, J., Chen, E., Yan, S., Lerman, K., \& Ferrara, E. (2020). Political polarization drives online conversations about COVID-19 in the United States. Human Behavior and Emerging Technologies, 2(3), 200-211. https://doi.org/https://doi.org/10.1002/HBE2.202

Joseph, N., Grover, P., Rao, P. K., \& Ilavarasan, P. V. (2017). Deep analyzing public conversations: Insights from twitter analytics for policy makers. In A. K. Kar, P. V. Ilavarasan, M. P. Gupta, Y. K. Dwivedi, M. Mäntymäki, M. Janssen, A. Simintiras, \& S. Al-Sharhan (Eds.), Digital Nations -- Smart Cities, Innovation, and Sustainability (pp. 239-250). Springer International Publishing. https://doi.org/https://doi.org/10.1007/978-3-319-68557-1_22

Jungherr, A. (2016). Twitter use in election campaigns: A systematic literature review. Journal of Information Technology and Politics, 13(1), 72-91. https://doi.org/https://doi.org/10.1080/19331681.2015.1132401

Jungherr, Andreas, Schoen, H., \& Pascal Jürgens. (2016). The Mediation of Politics through Twitter: An Analysis of Messages posted during the Campaign for the German Federal Election 2013No Title. Journal of Computer-Mediated Communication, 21(1), 50-68. https://doi.org/https://doi.org/10.1111/jcc4.12143

Kadijat, K. K., Ayotunde, K. A., \& Haroon-Sulyman, S. O. (2020). Twitter Discourse on the Pre-Presidential Election Campaign in Nigeria. Jurnal The Messenger, 12(2), 134-151. https://doi.org/http://dx.doi.org/10.26623/themessenger.v12i2.2457

Katz, E. (1959). Mass Communications Research and the Study of Popular Culture: An Editorial Note on a Possible Future for This Journal. Studies in Public Communication, 2 , $1-6$. https://repository.upenn.edu/asc_papers/165?utm_source=repository.upenn.edu \%2Fasc_papers\%2F165\&utm_medium=PDF\&utm_campaign=PDFCoverPages

Kaur, M., \& Verma, R. (2018). Demographics, Social Media Usage, and Political Engagement in Punjab. Indian Journal of Marketing, 48(11). https://doi.org/10.17010/ijom/2018/v48/i11/137984

Kaur, M., Verma, R., \& Otoo, F. N. K. (2021). Emotions in leader's crisis communication: Twitter sentiment analysis during COVID-19 outbreak. Journal of Human Behavior in the Social Environment, 31(1-4), 362-372. https://doi.org/https://doi.org/10.1080/10911359.2020.1829239

Kaur, R., \& Ranjan, S. (2020). Sentiment Analysis of 21 daysCOVID-19 Indian lockdown tweets. International Joujrnal of Advance Research in Sciebnce and 
Enginering, 9(7), 37-44. http://ijarse.com/images/fullpdf/1595226537_G234.pdf Khan, G. F., Yoon, H. Y., \& Park, H. W. (2014). Social media communication strategies of government agencies: Twitter use in Korea and the USA. Asian Journal of Communication, 24(1), 60-78. https://doi.org/10.1080/01292986.2013.851723

Kruikemeier, S. (2014). Computers in Human Behavior How political candidates use Twitter and the impact on votes. Computers in Human Behavior, 34, 131-139. https://doi.org/https://doi.org/10.1016/j.chb.2014.01.025

Leo, L. (2020). Covid-19: Centre designates all metros as red zones for lockdown postMay 3. Livemint. https://www.livemint.com/politics/policy/centre-designates-allmetros-as-red-zones-for-lockdown-post-may-3-11588271997748.html

Lewis, K. M. (2000). When Leaders Display Emotion: How Followers Respond to Negative Emotional Expression of Male and Female Leaders. Journal of Organizational Behavior, 23(2), 221-234. https://www.jstor.org/stable/3100307

Limaye, R. J., Sauer, M., Ali, J., Bernstein, J., Wahl, B., Barnhill, A., \& Labrique, A. (2020). Building trust while influencing online COVID-19 content in the social media world. The Lancet Digital Health, 2(6), e277-e278. https://doi.org/https://doi.org/10.1016/S2589-7500(20)30084-4

Lin, J.-S., \& Himelboim, I. (2019). Political Brand Communities as Social Network Clusters: Winning and Trailing Candidates in the GOP 2016 Primary Elections. Journal of Political Marketing, 18(1-2), 119-147. https://doi.org/https://doi.org/10.1080/15377857.2018.1478661

Manguri, K. H., Ramadhan, R. N., \& Amin, P. R. M. (2020). Twitter Sentiment Analysis on Worldwide COVID-19 Outbreaks. Kurdistan Journal of Applied Research, 5(Special Issue on Coronavirus (COVID-19)), 23-30. https://doi.org/https://doi.org/10.24017/covid.3

Merkley, E., Bridgman, A., Loewen, P. J., Owen, T., Ruths, D., \& Zhilin, O. (2020). A rare moment of cross-partisan consensus: Elite and public response to the CoviD19 pandemic in Canada. Canadian Journal of Political Science, 53(2), 311-318. https://doi.org/10.1017/S0008423920000311

O’Connor, B., Balasubramanyan, R., \& Routledge, B. R., \& Smith, N. A. (2010). From tweets to polls: Linking text sentiment to public opinion time series. Proceedings of Fourth International AAAI Conference on Weblogs and Social Media, 122129. https://www.aaai.org/Library/ICWSM/icwsm10contents.php

Parmelee, J. H., \& Bichard, S. L. (2012). Politics and the Twitter Revolution: How Tweets Influence the Relationship Between Political Leaders and the Public. Lexington Books.

Phillips, A. C., Irfan, M. T., \& Ostertag-Hill, L. (2021). Spheres of legislation: polarization and most influential nodes in behavioral context. Computational Social Networks, 8(1), 1-51. https://doi.org/https://doi.org/10.1186/s40649-02100091-2

Pulido, C. M., Villarejo-Carballido, B., Redondo-Sama, G., \& Gómez, A. (2020). COVID-19 infodemic: More retweets for science-based information on coronavirus than for false information. International Sociology, 35(4), 377-392. https://doi.org/https://doi.org/10.1177/0268580920914755

Rahman, S. A. (2020). Overcome by anxiety: Indians in lockdown many can ill afford. The Guardian. https://www.theguardian.com/world/2020/mar/25/overcome-byanxiety-india-in-lockdown-many-can-ill-afford

Ranjan, S. (2018). Analyzing Social Media Community Sentiment Score for Prediction 
of Success of Bollywood Movies. International Journal of Latest Engineering and Management Research, 3(Special Issue: CTEMIT-2018), 80-88. http://www.ijlemr.com/papers/CTEMIT/part-2/T1-143.pdf

Reid, D. (2020). India confirms its first coronavirus case. CNBC. https://www.cnbc.com/2020/01/30/india-confirms-first-case-of-thecoronavirus.html

Rufai, S. R., \& Bunce, C. (2020). World leaders' usage of Twitter in response to the COVID-19 pandemic: a content analysis. Journal of Public Health, 42(3), https://doi.org/10.1093/pubmed/fdaa049. https://doi.org/https://doi.org/10.1093/pubmed/fdaa049

Sawyer, R., \& Chen, G. M. (2012). The Impact of Social Media on Intercultural Adaptation. Intercultural Communication Studies, 21(2), 151-169. http://digitalcommons.uri.edu/com_facpubs

Sheldon, P., \& Bryant, K. (2016). Instagram: Motives for its use and relationship to narcissism and contextual age. Computers in Human Behavior, 58, 89-97. https://doi.org/https://doi.org/10.1016/j.chb.2015.12.059

Smith, K. (2020). 60 Incredible and Interesting Twitter Stats and Statistics. Brandwatch. https://www.brandwatch.com/blog/twitter-stats-and-statistics/

Spinney, L. (2020). The coronavirus slayer! How Kerala's rock star health minister helped save it from Covid-19. The Guardian. https://www.theguardian.com/world/2020/may/14/the-coronavirus-slayer-howkeralas-rock-star-health-minister-helped-save-it-from-covid-19

Statista. (2021). Number of Twitter users worldwide from 2014 to 2024. Statista. https://www.statista.com/topics/737/twitter/

Stier, S., Bleier, A., Lietz, H., \& Strohmaier, M. (2018). Election Campaigning on Social Media : Politicians, Audiences, and the Mediation of Political Communication on Facebook and Twitter Election Campaigning on Social Media : Politicians , Audiences , and the Mediation of Political. Political Communication, 35(1), 5074. https://doi.org/https://doi.org/10.1080/10584609.2017.1334728

Tang, L., Bie, B., Park, S. E., \& Zhi, D. (2018). Social media and outbreaks of emerging infectious diseases: A systematic review of literature. American Journal of Infection Control, 46(9), 962-972. https://doi.org/https://doi.org/10.1016/j.ajic.2018.02.010

Tejedor, S., Cervi, L., Tusa, F., Portales, M., \& Zabotina, M. (2020). Information on the covid-19 pandemic in daily newspapers' front pages: Case study of Spain and Italy. International Journal of Environmental Research and Public Health, 17(17), 1-16. https://doi.org/https://doi.org/10.3390/ijerph17176330

Ullah, F., \& Lee, S. (2016). Social content recommendation based on spatial-temporal aware diffusion modeling in social networks. Symmetry, 8(9), 89. https://doi.org/; https://doi.org/10.3390/sym8090089

WHO. (2020a). Naming the coronavirus disease (COVID-19) and the virus that causes it. WHO. https://www.who.int/emergencies/diseases/novel-coronavirus2019/technical-guidance/naming-the-coronavirus-disease-(covid-2019)-and-thevirus-that-causes-it

WHO. (2020b). WHO releases guidelines to help countries maintain essential health services during the COVID-19 pandemic. WHO. https://www.who.int/news/item/30-03-2020-who-releases-guidelines-to-helpcountries-maintain-essential-health-services-during-the-covid-19-pandemic 
World Health Organization. (2020). Coronavirusdisease (COVID-19) Situation Report10. World Health Organization. https://www.who.int/docs/defaultsource/coronaviruse/situation-reports/20200503-covid-19-sitrep104.pdf?sfvrsn=53328f46_2.

Yadav, J. (2020). Indians are fighting against coronavirus and BJP IT cell is fighting against Indians. The Print. https://theprint.in/opinion/pov/indians-are-fightingagainst-coronavirus-and-bjp-it-cell-is-fighting-against-indians/395058/ 